\section{DERECHOS POLÍTICOS, CONSTITUCIONALISMO Y SEPARACIÓN DE PODERES}

\author{
Andrea Greppi \\ Universidad Carlos III de Madrid
}

\section{POLITICAL RIGHTS, CONSTITUTIONALISM AND SEPARATION OF POWERS}

\begin{abstract}
In recent years, the literature on democracy did not pay much attention to the relationship between political rights and separation of powers, probably because of the influence of rights-constitutionalism which has preferred the anti-majoritarian view. The aim of this article is to point out several transformations that determine a radical change in the conditions of exercise of political rights and are associated with the decline of separation of powers in contemporary constitutional systems. This analysis is based on the conceptual tools developed by Luigi Ferrajoli in Principia luris and, particularly, on the distinction between functions of government and functions of guarantee. The final suggestion is that the epistemic distinction between political judgment and knowledge is essential in any form of representative democracy but relies on pragmatic rules about distribution of epistemic authority that became extremely unstable in contemporary societies.
\end{abstract}

KEY WORDS: Separation of powers; political rights; constitucionalism; epistemic authority; crisis of democracy.

\section{1) Derechos políticos Y CONDiciones INSTITUCIONALES DE LA DEMOCRACIA}

En su representación más gráfica, los procesos de legitimación democrática siguen un esquema ascendente y reposan sobre el derecho de los ciudadanos a tomar parte en pie de igualdad en las decisiones que les afectan. A más participación, más democracia. Se entiende que cuanto más extensas y profundas sean las garantías de la libertad política, mayor calidad tendrán los procesos de autodeterminación democrática. Sucede, sin embargo, que las condiciones para el ejercicio de los derechos de participación política son más complejas de lo que se suele reconocer. Cualquier noción mínimamente fiable de calidad democrática deberá incluir la referencia a un amplio abanico de factores institucionales y sociales. En este sentido, la multiplicación de las ocasiones de participación no produce necesariamente una ganancia en la calidad del proceso. No basta con ir a votar más veces para que haya más democracia. Se necesita
RESUMEN: La relación entre derechos políticos y separación de poderes no ha recibido demasiada atención en el pensamiento democrático de los últimos años donde ha sido predominante una visión centrada en el constitucionalismo de los derechos, con una explícita orientación contra-mayoritaria. El propósito de este artículo es indicar una serie de transformaciones que afectan de manera determinante a la estructura de separación de poderes de nuestros sistemas constitucionales y que suponen un cambio radical en las condiciones de ejercicio de los derechos políticos. Se utiliza para ello el aparato conceptual desarrollado por Luigi Ferrajoli en su reciente Principia luris y, en particular, la distinción entre funciones de gobierno y funciones de garantía. La sugerencia con la que se cierra el trabajo es que la distinción entre juicio político y conocimiento cierto es indispensable en el diseño institucional de cualquier democracia representativa pero reposa sobre un conjunto de reglas pragmáticas acerca de la distribución de la autoridad epistémica que se han vuelto extremadamente inestables en las sociedades contemporáneas.

PALABRAS CLAVE: Separación de poderes; derechos políticos; constitucionalismo; autoridad epistémica; crisis de la democracia.

que los ciudadanos puedan formarse una opinión y que su opinión tenga un peso real en la toma de decisiones, en las materias más importantes.

En los últimos años ha habido un gran interés por explorar diferentes iniciativas para incrementar la intensidad de la democracia. Algunas de estas propuestas se han llevado a la práctica y han tenido un éxito indiscutible. No obstante, este tipo de experiencias no han dejado de ocupar una posición periférica tanto en la teoría como en la práctica, fundamentalmente porque es altamente improbable que sociedades tan complejas como las nuestras puedan ser gobernadas por medio de alguna variante actualizada de la democracia directa. Por supuesto, las modalidades de la representación política evolucionan y pueden ser complementadas con mecanismos participativos de los más diversos tipos. Sin embargo, es difícil creer que las prótesis o suplementos puedan reemplazar las instituciones típicas de la democracia moderna. 
Alguien responderá que, lejos de ser decorativas, estas iniciativas son indispensables para revitalizar la estructura civil y política de las sociedades democráticas. Pero esta respuesta está lejos de ser definitiva. Es verdad que la participación es imprescindible para asegurar la estabilidad de las instituciones democráticas; pero también que los mecanismos complementarios de participación no surgen por generación espontánea y no se administran solos. Requieren el respaldo de instituciones comprometidas con su desarrollo, y éstas, a su vez, es deseable que estén sujetas a formas efectivas de control. Eso nos devuelve al punto de partida. Más participación, sin precauciones, no es garantía de una mejora en el déficit de legitimidad democrática. Cuando se oye reivindicar con tanto entusiasmo la gran novedad de los experimentos participativos, a veces da la impresión de que se está intentando comenzar la casa por el tejado. Se pretenden reparar las grietas del viejo edificio sin antes haber comprobado si los pilares son bastante sólidos para aguantar la obra.

En las próximas páginas voy a ocuparme de la degradación de los derechos de participación política como consecuencia de los desequilibrios del marco institucional en que esos derechos se ejercen, esto es, en la estructura de separación de poderes que caracteriza a las democracias representativas. Para que un ciudadano pueda ejercer sus derechos de participación, y para que esa participación política sea valiosa y efectiva, han de darse una serie de condiciones. Se necesita, para empezar, la garantía de los derechos de libertad, así como de las demás garantías básicas del estado de derecho. También se necesita, en segundo lugar, que los ciudadanos tengan posibilidades reales de hacer uso de las facultades que la constitución le otorga, esto es, que dispongan tanto de los recursos materiales como de la información necesaria para participar de forma responsable. Se necesita también -y esta es la cuestión que me interesa- la presencia de un marco institucional en el que estén claramente definidas y delimitadas las competencias de los poderes que intervienen en el proceso de formación de la voluntad política. Sin ese marco, el derecho-poder de participación reconocido a todos los ciudadanos carece de contenido'.

\section{2) El estado de la cuestión: las mayorías bajo SOSPECHA}

Antes de entrar en el núcleo de mi argumento me detendré en la relativa poca fortuna que la reivindicación de los de- rechos políticos ha tenido en el pensamiento democrático de los últimos años. Nada nuevo: las mayorías han estado y siguen estando bajo sospecha². Más sorprendente parece la posición secundaria que ocupa el principio de separación de poderes en el amplísimo debate contemporáneo sobre el constitucionalismo.

En el amplísimo debate sobre constitucionalismo y democracia, la posición de los derechos políticos ha quedado algo oscurecida por la contraposición, forzada e imprecisa, entre mayorías y derechos. Apelando a una concepción "sustancial" y no "meramente procedimental" de la democracia, los neoconstitucionalistas han hecho hincapié en los límites constitucionales a la voluntad democrática y han argumentado que la autonomía no es el único ni es el más importante de los valores sobre los que se asienta la legitimidad de nuestros sistemas políticos ${ }^{3}$. El renovado interés por esta tesis responde a un determinado diagnóstico sobre los problemas y las perspectivas de desarrollo de las democracias contemporáneas. Se tiende a pensar -me permito resumir esquemáticamente una opinión difusa- que las mejores perspectivas para la recuperación del déficit de legitimidad de las democracias actuales consisten en el desarrollo de garantías contramayoritarias, pues en ellas se encuentra el remedio más eficaz contra la mala política, en todas sus formas, y especialmente contra la ocupación partidista del poder político, económico y mediático. Con ello se reafirma la superioridad del gobierno de las leyes sobre el gobierno de los hombres y se promueve una nueva vuelta de tuerca en la progresiva construcción del Estado (constitucional) de derecho.

En la apuesta por el constitucionalismo de los derechos aflora además la consideración típicamente realista sobre el impacto infinitesimal del voto de cada elector, cuyo valor es poco más que simbólico. A eso se suma la presencia de numerosos factores correctivos que distorsionan la igualdad aritmética en la representación, atendiendo a las muy diversas exigencias -gobernabilidad, composición territorial del Estado, reconocimiento de minorias- que condicionan el diseño de los sistemas electorales (Dworkin, 2003, 219 y ss.). Desde este punto de vista, la regla de decisión por mayorías no es más que una entre las muchas técnicas posibles, y ni siquiera la más importante, para alcanzar los fines a los que responde el marco institucional ${ }^{4}$. Frente a las debilidades de la concepción 
mayoritarista de la democracia, los partidarios del nuevo constitucionalismo persiguen una concepción distinta, que le resta protagonismo a las reglas procedimentales y, por el contrario, sitúa en el centro del proceso político el principio de igual consideración y respeto de todos los miembros de la asociación política. Las mayorías pueden equivocarse, desviarse de la decisión correcta y no tienen ninguna vía de acceso privilegiada, más fiable que otras, a la verdad en materia moral (Nino, 1997). Y aunque lográramos demostrar que las mayorías tienden a equivocarse menos que las minorías, lo cierto es que unas y otras se equivocan, con trágicas consecuencias, y eso bastaría para justificar el establecimiento de un sistema de frenos y contrapesos (Zagrebelsky, 1995, 114-115). En última instancia, el atrincheramiento de las reglas del juego frente a la voluntad de quienes intenten subvertirlas parece la medida más inteligente para asegurar la supervivencia de la democracia (Ely, 1997).

El problema, en este punto, es que el argumento de la mayor capacidad epistémica de los guardianes de la constitución respecto de las mayorias es siempre reversible y no faltan quienes han planteado la posibilidad de darle la vuelta (por todos, Waldron, 2005). Los partidarios del reflujo democrático pueden mostrar sin demasiada dificultad que la probabilidad del "error" no se distribuye de forma constante entre los guardianes y las mayorias y que, por el contrario, depende de multitud de factores institucionales y sociales. Es verdad que las mayorías no están nunca a salvo de influencias perversas y juegos propagandísticos, pero también que la independencia de magistratura frente al poder político y frente a los humores populares, por más garantías que se establezcan al respecto, es poco más que una ilusión. Desde una perspectiva estrictamente pragmática cabe plantearse qué mecanismos de control podrán mantenerse a salvo de la creciente batalla política -en el sentido puramente partidista- por el control sobre la interpretación constitucional. Porque a nadie se le oculta que el incremento de las dificultades interpretativas va en función del número de materias protegidas por derechos fundamentales. Cuanto más ancho sea el "ámbito de la constitución" y el número de decisiones controvertidas, menor será el consenso y más difícil encontrar soluciones socialmente aceptables. Reconocer que en casos como esos las mayorías pueden tener la última palabra quizá no sea una conclusión tan descabellada.
A partir de ahí, se reabre la valoración de los resultados alcanzados en el debate sobre el constitucionalismo contemporáneo. Parece, en efecto, que los argumentos de los neoconstitucionalistas no acaban de poner contra las cuerdas la tesis de quienes reivindican el valor intrínseco, y no meramente instrumental, de la libertad política. Si nos tomamos en serio la tesis de la continuidad y complementariedad entre los distintos tipos de derechos -con Habermas, la tesis de la cooriginariedad entre libertad positiva y negativa- llegamos inevitablemente a la conclusión de que les corresponde a los ciudadanos, que son la fuente última de la autoridad, revisar y reformular el contenido de los derechos y libertades que forman el proyecto constitucional. Frente a un argumento tan radical, los neoconstitucionalistas pueden todavía replicar que los procedimientos de representación política están hoy, de hecho, tan deteriorados que son incapaces de producir más legitimidad que las instituciones contramayoritarias. Como las votaciones de los parlamentos no son más "democráticas" ni representativas que las votaciones que tienen lugar en el seno de las cortes constitucionales, vienen a decir, quedémonos con éstas, que por lo menos suelen tener mayor prestigio.

¿Quién sale ganando en el debate? No es fácil decirlo, y más bien parece que al final del recorrido se llega a un punto de relativo equilibrio entre las razones de las dos partes, donde no es difícil imaginar la progresiva convergencia hacia alguna de las posibles variantes de un constitucionalismo débil. Hay acuerdo en evitar la contraposición entre las dos posiciones extremas -que podríamos describir como mayoritarismo y anti-mayoritarismo- y en aceptar que el balance correcto entre valores intrínsecos del procedimiento y valores sustanciales depende en última instancia de factores contextuales. Que haya razones para establecer reglas en las que marcan las condiciones mínimas para el buen funcionamiento de las instituciones democráticas no implica que dichas reglas deban -ni puedan- quedar definitivamente sustraídas al juego de la democracia ${ }^{5}$. Un equilibrio razonable entre constitución y mayorías es aquel en el que se combinan ciertas restricciones a la voluntad de las mayorías, con un principio general de autorrestricción judicial y de deferencia a la voluntad del legislador, y en el que se establecen mecanismos de enfriamiento para las decisiones más difíciles, especialmente para aquellas que suponen una mutación constitucional, reservando la última palabra a las mayorías, en un marco procedimental de separación de poderes (cfr. Hierro, 2007). 
Pero la solución no es del todo pacífica. Mientras el péndulo de la teoría sigue oscilando entre la defensa de la voluntad de las mayorías y la reivindicación de mecanismos contra-mayoritarios de decisión, entre la demanda de más derechos políticos y el establecimiento de nuevas garantías, nos preguntamos si ese marco procedimental en el que se inserta el juego de las mayorias funciona como se supone que lo hace. Y es que, en efecto, la relevancia de los derechos de participación no depende sólo de su mayor o menor extensión, sino también de la estructura constitucional en que se insertan. Teniendo en cuenta las condiciones de las democracias actuales, ¿qué función cumplen hoy los derechos políticos? ¿Para qué valen? La respuesta más obvia consiste en decir que valen para elegir representantes, o para sancionar a los representantes durante la legislatura anterior. Pero una respuesta de este tipo es poco significativa. En efecto, si afirmo que los derechos políticos tienden hoy a degradarse, a quedar vacíos de contenido, no es porque hayan sido derogados; ni tampoco porque considere que, desde el punto de vista sustancial, las instituciones representativas - partidos, sindicatos, parlamentos, etc.- lo son cada vez menos; ni tampoco porque considere, como se hace a menudo en la polémica sobre el neo-constitucionalismo, que los mecanismos contramayoritarios de garantía han invadido, de forma ilegítima, el espacio de autodeterminación de los ciudadanos. Me interesa el vaciamiento de los derechos políticos como consecuencia de la progresiva disolución del entramado institucional en que tales derechos-poderes se insertan, un marco que debería estar basado en alguna de las muchas variantes del principio de separación de poderes.

\section{3) La estruCtura JuRídica dE LA DEMOCRACIA: PLAN INICIAL Y DESARROLLO}

De la forma más esquemática, el proceso de legitimación democrática supone algo más que la atribución del derecho de sufragio activo y pasivo a todos los ciudadanos y la celebración de elecciones limpias y regulares. Supone además la existencia de una estructura política en la que se reconoce tanto el principio de legalidad como el principio de separación de poderes ${ }^{6}$. Ley emana del proceso de participación democrática, expresa la voluntad popular, orienta las decisiones del poder ejecutivo y legitima las decisiones judiciales. Al menos en teoría. A lo largo del siglo XX, e incluso antes, en cualquiera de los tres principales ámbitos geográficos en los que se desarrolla históricamente el constitucionalismo democrático (en Inglaterra, en Estados Unidos y en Francia), el modelo más elemental de relación entre los tres poderes quedó desvirtuado, entre otros factores, por la aparición de un aparato burocrático estatal de dimensiones muy superiores a las previstas inicialmente, que modificaba sustancialmente los mecanismos de control democrático (Vile, 2007, 351 y ss.). Desde entonces, los objetivos de equilibrio y control, representación y responsabilidad, participación y eficacia se han mantenido vigentes pero han dado lugar a fórmulas institucionales muy diferentes y cambiantes.

Considérense, al menos, los siguientes factores de cambio: (a) han aparecido estructuras multi-funcionales, diseñadas para cumplir objetivos, implementar planes, administrar programas y que pueden desempeñar, por razones de eficacia, funciones distintas; (b) en relación con la función ejecutiva, se ha difuminado la distinción entre ejecución administrativa y dirección política, quedando finalmente ambas sometidas a un control de carácter jurisdiccional; (c) el legislativo ha perdido el monopolio de la producción normativa, al menos por dos razones distintas: por un lado, por el incremento de los márgenes de discrecionalidad judicial dada la creciente complejidad del ordenamiento $y_{\text {, }}$ por otro, por el reforzamiento de los órganos puramente técnicos de las grandes organizaciones burocráticas que generan pautas normativas que el legislativo se ve forzado a asumir pasivamente; (d) la función de control se ha dispersado, en el sentido de que ya no se sustancia sólo ante los tribunales o en el momento electoral, sino que se ejerce de manera difusa a través de múltiples instancias más complejas y menos visibles; y finalmente (e) junto a las tres funciones clásicas, ha aparecido y ha ido cobrando cada vez mayor peso la función de coordinación entre los distintos poderes y niveles institucionales.

La relevancia de estos cambios sobre el contexto institucional en que se insertan los derechos políticos es evidente. Y la conclusión inmediata, aunque seguramente apresurada, es que la disolución del modelo clásico de separación de poderes va a traer consigo el fin de la democracia representativa, al menos en la forma en que la hemos conocido hasta la fecha. Si el pueblo ya no habla a través de las leyes y se limita a entrar en escena de vez en cuando para deponer a las élites en el gobierno, parece inevitable 
concluir que el reconocimiento universal de los derechos políticos se ha convertido en poco más que un elemento marginal del sistema. Una más entre las muchas piezas de una organización compleja, que puede tener múltiples equivalentes funcionales. Para evitar esta conclusión -que, sin embargo, no podemos pasar por alto a la ligera- es preciso adentrarse en el análisis de la estructura jurídica de la democracia constitucional.

Desde el punto de vista procedimental, explica Luigi Ferrajoli en Principia luris, la democracia puede ser descrita como "el conjunto de las reglas que atribuyen al pueblo, o mejor, a la mayoría de sus miembros el poder para tomar [ciertas] decisiones, de forma directa o por medio de representantes" (Ferrajoli, 2007, t. II, 5). Esta caracterización del procedimiento democrático supone la existencia de un doble sistema de reglas: de un lado, las reglas de competencia, que atribuyen poderes; de otro, las reglas que establecen límites y vínculos de carácter sustantivo o de contenido al ejercicio de dichas competencias. Puede decirse que la constitución tiene por objeto tanto la sintaxis -los procedimientos-, como la semántica -los contenidos- de la democracia (2007, t. II, 99-100). Unas y otras son imprescindibles para hablar su lenguaje, para jugar su juego. Si el procedimiento careciera de límites sustantivos, si no hubiera límites a la actuación de los poderes, estos serían arbitrarios. Cualquier poder podría hacer cualquier cosa y en cualquier momento. Lo que le interesa a Ferrajoli, conforme a la tradición del constitucionalismo viejo y nuevo, son los poderes, tanto públicos como privados, que para ser democráticos han de estar sometidos a derecho ${ }^{7}$. En este sentido, las normas que atribuyen a cada ciudadano el derecho-poder de intervenir en el proceso de formación de la voluntad política pueden ser interpretadas como normas que producen y distribuyen "fragmentos de soberanía" (2007, t. II, 11; 14; y apdos. $13.10 ; 14.1)$. La soberanía del ciudadano, su poder de decisión, se extiende hasta el punto que las reglas indican, pero no más allá. Está limitado por ley. En este sentido, la existencia de procedimientos de decisión es garantía de que cada uno de los "fragmentos" de poder soberano no llegará a excederse nunca de los límites que le corresponden, no invadirá el espacio de poder que el ordenamiento le atribuye a los demás "fragmentos". Procedimientos de decisión y derechos políticos son dos piezas de un mismo engranaje y comparten un mismo destino. La confusión de los poderes es causa y efecto de la crisis de la ley y ambas contribuyen a vaciar de contenido - de influencia políticalos fragmentos de soberanía atribuidos a los electores (cfr. Bovero, 1998; Guastini, 1998; Troper, 2001).

En la lectura de Ferrajoli, la respuesta frente a estos desarrollos patológicos es doble. Consiste, por un lado, en reiterar el carácter estipulativo de los postulados básicos de la teoría del derecho y de las normas que definen el sistema de los derechos fundamentales. Esto permite sostener el carácter estrictamente "político", y por tanto "democrático", de los fundamentos del sistema constitucional. Por otro lado, se afirma el carácter tendencialmente cognitivo de los procesos de aplicación del derecho, desde la constitución en adelante. Aparece así un factor epistémico sin el que sería imposible explicar la arquitectura del sistema de separación de poderes: existe derecho -y Estado de derecho- porque es posible conocer tanto el significado de las normas como de los hechos a los que el derecho se aplica ${ }^{8}$. Esto implica que tanto el legislador como el intérprete habrán de tener en sus manos los instrumentos cognitivos necesarios para desempeñar con el suficiente grado de objetividad la labor que se les encomienda: el legislador, el conocimiento experto necesario para dictar la ley; el jurista, el conocimiento técnico necesario para aplicarla. Son dos funciones distintas, dos poderes distintos, y dos fundamentos epistémicos distintos. Es obvio que aparecerán toda clase obstáculos y dificultades de orden práctico. Será necesario echar las cuentas con cierto margen fisiológico de discrecionalidad (2007, t. I, 555), pero la distinción entre los dos tipos de funciones es clara y toda desviación equivale a un desmentido de las reglas implícitas básicas de funcionamiento de la democracia.

Ahora bien, que el principio de división y separación de poderes haya sido un factor determinante en el desarrollo de la estructura jurídica de la democracia constitucional no implica -y aquí es donde comienzan las dudas- que esté por encima de las contingencias históricas. De hecho, reposa sobre un conjunto de presupuestos teóricos y politicos altamente conflictivos. La diferencia entre funciones de gobierno y funciones de garantía sólo tiene sentido si consideramos que es posible distinguir, con suficiente claridad, entre lo opinable y lo cierto, dos esferas del juicio que se suponen radicalmente distintas y a las que se atribuye un estatuto epistémico diferenciado (2007, t. I, 563 y ss.). El problema está en que la frontera entre estas dos esferas no es ni mucho menos obvia. A medida que se 
difumina, con ella se viene abajo la diferencia entre poderes encargados de crear y órganos encargados de seguir reglas, entre legislar y aplicar el derecho. La "fisiología" del saber-poder de los legisladores y los jueces no es ni mucho menos inmune a un conjunto de transformaciones sociales y culturales de muy hondo calado y que son determinantes para tratar la cuestión que nos ocupa.

\section{4) AnÁlisis de LAS funciones de GOBIERno Y DE GARANTÍA}

La conclusión de este ensayo va a ser que la progresiva marginación de los derechos políticos, su creciente irrelevancia en los procesos de toma de decisiones, está relacionada con la disolución del ideal de la separación de poderes, y ésta a su vez con un cambio en las pautas sociales de atribución de la autoridad epistémica. Pero antes de llegar a eso conviene mencionar, siquiera esquemáticamente, algunos de los síntomas a través de los que se manifiesta la crisis del principio de separación de poderes, y tantear su calado. Para ello distinguiremos, con Ferrajoli, entre las dos funciones básicas -de gobierno y de garantía- y los poderes -de disposición y de cogniciónasociados a ellas.

\section{4.a) Funciones de gobierno}

La ficción de la voluntad democrática, fuente de legitimidad de los distintos poderes del Estado, está sometida en nuestro tiempo a una presión extraordinaria. Nos enfrentamos a un conjunto de transformaciones que afectan a los instrumentos, a los contenidos y a los actores que supuestamente contribuyen a determinarla.

(1) En cuanto a los instrumentos mediante los cuales se expresa la voluntad popular, nos encontramos en una situación en la que se evapora el postulado democrático de la centralidad de la ley, así como el principio subyacente de la soberanía del legislador. En la "edad de la descodificación" el texto de la ley ya no es el referente central de la unidad y coherencia del sistema jurídico. Este proceso es evidente en el derecho privado, donde hace tiempo que se ha producido la multiplicación de las legislaciones especiales. En la última fase de este proceso, se ha producido un verdadero desplazamiento del legislador nacional con el desarrollo del derecho uniforme del comercio internacional, que es derecho consuetudinario, extra-legal y extrajurisdiccional, pero que tiene una importancia económica y estratégica incalculable. La eficacia de este nuevo derecho está contrastada y su expansión acompaña los avances de la globalización económica (2007, t. II, 531). Es derecho sin Estado, fruto de la voluntad de agentes que actúan al margen de cualquier lógica de separación funcional de poderes. Desarrollos paralelos están teniendo lugar incluso en materia penal, un campo en el que la cultura jurídica ilustrada había afirmado el principio de la más estricta legalidad. Las señales están a la vista: inflación legislativa, indeterminación de los tipos penales, excepcionalidad de los procedimientos, proliferación de las figuras de mera sospecha o de peligro, incremento exponencial de los márgenes interpretativos por la baja calidad técnica de la producción legal; proliferación de la legislación de emergencia (2007, t. II, 368-369; 539 y ss).

(2) Desde el punto de vista de los contenidos de las normas que deberian expresar la voluntad popular, nos enfrentamos a una drástica disminución de la capacidad regulativa del derecho. Debemos señalar aquí los distintos factores que inciden en el paso de un derecho de reglas a un derecho de principios, un derecho que establece fines, objetivos, programas, directrices, criterios flexibles e indeterminados de actuación, desplazando el momento crucial de la determinación del derecho del momento legislativo, donde se establecen de las palabras de la ley, al momento aplicativo o argumentativo, de la ponderación entre principios en vista de las circunstancias particulares del caso. La hipótesis es que estas técnicas normativas son particularmente adecuadas para la implementación de los nuevos modos de gobernanza9. Las normas tienden a volverse "reflexivas", se difuminan las pautas de interpretación dogmática, se altera su estructura jerárquica y se multiplican los espacios de resolución extra-judicial de conflictos. Desmintiendo las profecías weberianas sobre la racionalización del derecho, esta transformación apunta a una superación de las rigideces -la ineficiencia- del viejo derecho formalista, propio de organizaciones burocráticas y jerárquicas. Obsérvese, en todo caso, que los distintos procesos de des-regulación están absolutamente generalizados en cualquier sector y nivel del ordenamiento jurídico, tanto en ámbito local, como estatal, internacional y supranacional. El argumento más contundente para explicar este cambio es que el nuevo derecho es más "eficaz" que 
el viejo (Zürn; Joerges, 2005), de donde es fácil concluir que la voluntad del legislador democrático ha quedado descentrada y confiada a un conjunto indeterminado de normas administradas por un sistema no estructurado -confuso- de poderes.

(3) De la combinación de los anteriores elementos se deriva un profundo cambio en la estructura de los poderes públicos, que afecta tanto a la discrecionalidad del legislador, como a la discrecionalidad del ejecutivo. Por lo que respecta al legislativo, el ocaso de la ley nos conduce a una situación en la que el legislador es cada vez menos influyente. Es un legislador sumergido, por la proliferación normativa, a la que ni siquiera él puede sustraerse; un legislador impotente, por la diversificación de las fuentes nacionales e internacionales y la aparición de nuevas jurisdicciones que son independientes del derecho de origen legislativo; un legislador maniatado, despojado de competencias por los procesos de descentralización local y de integración supranacional, donde se hace un uso sistemático del principio de subsidiaridad. No menos intenso es el impacto de estas transformaciones sobre el ámbito de competencias del ejecutivo. En concreto, junto a la administración estatal, formalmente sometida al control y dirección de órganos de gobierno legitimados democráticamente, ha ido apareciendo una selva de organismos e instituciones cuasi-autónomos, no-gubernamentales pero directa o indirectamente controlados -por ejemplo, por la vía de la financiación- por instancias de tipo político, y encargados del desempeño de funciones públicas ${ }^{10}$. La consecuencia inmediata de la entrada en escena de estos nuevos actores es la disolución de la frontera entre Estado y no Estado, administración y sociedad civil, con la emergencia -que algunos celebran- de una zona intermedia en la que se despliegan los vínculos, los intereses y las fuerzas de la sociedad civil. Pero tiene también una segunda consecuencia, que suele quedar en segundo plano: la proliferación de organismos semi-públicos o semi-privados, que operan en condiciones remotamente parecidas a las del mercado, y con ámbitos competenciales flexibles, favorece la aparición de amplios márgenes de discrecionalidad no sólo en la "interpretación", sino también en la "identificación" del derecho aplicable. No es improbable que estos nuevos actores acaben reemplazando al legislador democrático cuando éste no pueda o no sepa o no quiera imponer un criterio propio. Estos nuevos sujetos híbridos absorben competencias que son, de hecho, legislativas y ejecutivas, y legitiman su actuación por la vía de los resultados, afirmando que ellos son capaces de decidir "mejor" que el Estado.

\section{4.b) Funciones de garantía}

Los cambios no son menos relevantes en lo que respecta a las funciones de garantía y afectan tanto a las modalidades, como a la titularidad y a la estructura de los poderes que tienen formalmente atribuida dicha función. En general, nos enfrentamos al desbordamiento y a la saturación de los mecanismos jurisdiccionales de garantía y a la sustitución de tales mecanismos por otros distintos, formales e informales, que cumplen la función de rendición de cuentas (por ejemplo, Bovens, 2001). La cuestión está en saber en qué medida estos nuevos mecanismos de control van a estar en el futuro vinculados a la voluntad popular.

(1) La transformación de muchas de las modalidades políticamente más relevantes del poder de garantía se asocia a la bien conocida expansión de los ámbitos de competencia del Estado social. En la última fase, y desde hace ya algunas décadas, los cambios responden a una evolución que es posible describir -con Giddens- con la idea del paso de un Estado asistencial, que produce bienes y servicios, a un Estado de bienestar positivo. Como acabo de apuntar, en la nueva situación pierde terreno el principio de la estricta aplicación de la ley y aparecen nuevos márgenes de discrecionalidad en el uso de los poderes públicos. Con arreglo a ello, la función de control tiende a transformarse en un juicio de adecuación sobre el uso de poderes discrecionales, donde juega un papel preponderante la competencia "técnica" tanto de los decisores como de los garantes. Es obvio que en estas condiciones cobran cada vez más importancia las formas de fiscalización o de evaluación que son más fiables desde el punto de vista epistémico. Podemos suponer que este proceso alcanzará una intensidad cualitativamente diferente con el paso inminente del Estado prestador de servicios al Estado regulador y evaluador, una vez agotado el debate entre partidarios del viejo modelo asistencial e intervencionista y partidarios de la desregulación y privatización de funciones públicas. Dado que la actividad de gobierno reposa cada vez más sobre principios técnicos de calidad y eficiencia en los servicios, así como sobre prácticas y códigos basados en el estado del arte en las materias concretas que son objeto de regulación, no tiene mucho sentido que el Estado insista 
en reclamar para sí el monopolio de la función directiva, una competencia exclusiva para la regulación de la actividad de los distintos actores sociales. Por lo demás, no tiene en sus manos ni los recursos materiales ni el conocimiento experto necesario para decirles a los actores que prestan los servicios qué es lo que tienen que hacer y cómo. Y la cuestión es saber dónde queda en este proceso la "vieja" exigencia democrática del imperio de la ley. ¿Cabe acaso imaginar que los órganos encargados de la formación de la voluntad popular asuman la responsabilidad de evaluar a los evaluadores? Alguien dirá que los estándares de evaluación no son "derecho" en sentido estricto, sino meros criterios instrumentales basados en la evidencia. Pero el problema seguirá siendo el mismo: el control de la adecuación-racionalidad, proporcionalidad, oportunidad, etc.- de las decisiones requiere un saber distinto al que poseen los titulares de las funciones de garantía, tanto en su vertiente jurisdiccional como en su vertiente administrativa.

(2) Por otra parte, dentro de y junto a los tradicionales órganos de garantía ha ido floreciendo una selva de autoridades y comisiones reguladoras, caracterizadas por la independencia orgánica respecto de las estructuras administrativas y judiciales. Ellas son las principales destinatarias -y en parte co-autoras- de ese nuevo derecho flexible al que aludía más arriba. Es cierto que la actividad de estos organismos y autoridades independientes estará siempre vinculada al cumplimiento de los fines marcados por las leyes y sujeta a diversas formas de control y rendición de cuentas, mediante procedimientos formales e informales. Sin embargo, es probable que, en la práctica, su poder llegue a ser tanto más fuerte cuanto más conflictiva y compleja sea la materia a la que se dedican. 0 , en negativo, cuanto más escasa y peor distribuida esté la autoridad epistémica. ¿Qué parlamento podrá enmendar la plana a estos mecanismos hiper-especializados de auto-regulación? ¿Qué gobierno podrá asumir, incluso en términos electorales, el coste de marcar directrices políticas que orienten una actuación que responde a criterios super-cualificados? Apresados entre dos males, no nos queda más remedio que recordar que la independencia no es una garantía "absoluta". En efecto, para que el poder frene al poder, conforme a la máxima de Montesquieu, es preciso que haya un terreno común en el que los distintos poderes entren en competencia. Una circunstancia que no se da en este caso. La hiper-especialización de las funciones hace que los órganos actúen en feudos incomunicados y tiendan a convertirse en guardianes incontrolables del interés general.

(3) Por último, la funciones de garantía se descomponen y dispersan siguiendo el proceso de descentralización de los viejos Estados territoriales y de integración en instancias supra-nacionales, un proceso que responde a la evidencia incontestable de que el Estado se ha vuelto demasiado grande para atender a las necesidades inmediatas y demasiado pequeño para hacer frente a los desafíos de nuestro tiempo. Las reglas de distribución de competencias, apelando sistemáticamente al principio de subsidiaridad, introducen un factor explosivo de complejidad en la estructura de los poderes jurisdiccionales. Se dice que avanzamos hacia la creación de formas políticas reticulares, de carácter cosmopolita y policéntrico, pero el hecho es que por el momento los pasos que se han dado en este sentido dejan mucho que desear, especialmente por lo que se refiere al desarrollo de mecanismos de garantía adecuados a la nueva estructura institucional. Y me refiero aquí a la idea de garantía en su más amplia acepción, que incluye tanto la garantía jurisdiccional como las distintas formas de rendición de cuentas. En concreto, y por lo que respecta a las formas de control difuso, es clamoroso el silencio de la opinión pública global, por más que alguien quiera ver los albores de una incipiente sociedad civil transnacional (Kaldor, 2005). En cambio, por lo que respecta a los controles jurisdiccionales, es evidente que el poder para decir el derecho debería ser el primero de los que debería atribuirse a un futuro soberano post-nacional y cosmopolita (no hay derecho común sin jurisdicción común). Lamentablemente, los avances en este sentido siguen siendo pobres y contradictorios (cfr. Ferrajoli, 2007, t. I, 567).

\section{5) El desafí Y el camino a eVitar}

Las indicaciones presentadas en el apartado anterior muestran, de forma incontestable, que el principio de separación de poderes está sometido hoy a un proceso de evidente disolución. De forma banal, lo que me interesa destacar es que las transformaciones en la estructura constitucional de separación de poderes tendrán implicaciones decisivas respecto del papel que juegan los derechos políticos como punto de referencia indispensable en los procesos de legitimación democrática. Si no se 
consigue salvar la distinción entre funciones de gobierno y funciones de garantía la "democracia" del mañana será una forma de gobierno radicalmente distinta a la democracia que conocemos. Es probable que siga habiendo elecciones, pero no habrá legislación democrática. El pueblo dejará de ser soberano.

A este respecto, la cuestión más interesante está en observar que para recuperar el principio de la separación no basta con modificar las reglas constitucionales. Lo que está en juego es algo más que un problema de diseño institucional, de invención de nuevos mecanismos de diferenciación y distribución de poderes. Así lo reconoce el propio Ferrajoli cuando afirma que "la cantidad y complejidad de las funciones públicas está creciendo enormemente" y que "este aumento de la complejidad de la esfera pública requeriría -en lugar de procesos regresivos de verticalización, confusión y concentración de los poderes [...]- un crecimiento paralelo, dentro de un sistema racional y unitario, de la diferenciación y distribución de los poderes, con todos los problemas consiguientes de eficiencia, funcionalidad y garantía" (2007, t. II, 194-195; las cursivas son mías).

Aumentar la complejidad del derecho -y de la ciencia jurídica- hasta equilibrar la complejidad social: este sería el desafío. Sin embargo, hemos de tener en cuenta que todo incremento de la complejidad tiene un coste y, por eso, no puede crecer indefinidamente. La impresión generalizada, en tiempos de globalización, es que la realidad amenaza con desbordar, o ha desbordado ya, al menos en muchos sectores, la capacidad de regulación del derecho. La brecha entre los lenguajes naturales de la economía o la política y el lenguaje artificial del derecho se encuentra ya en los límites de lo tolerable, en la frontera en que las palabras de la constitución se convierten en puros enunciados vacíos de contenido. Hay quienes aspiran a cubrir esa brecha recuperando la capacidad argumentativa del derecho, o el nexo entre derecho y razón pública. No es ésta -exactamente- la opción de Ferrajoli. Él apuesta más bien por compensar el déficit de credibilidad del derecho apelando al compromiso ético, al "sentido cívico de solidaridad y reciprocidad", a la "aceptación común" de un pacto de convivencia basado en el reconocimiento de la universalidad e indivisibilidad de los derechos fundamentales (2007, t. II, 100). De aquí la responsabilidad fundamental de los juristas a quienes les corresponde la labor determinante de construcción y reconstrucción del lenguaje jurídico, y más concretamente de mediación entre los lenguajes naturales, en que se formulan originariamente las demandas y expectativas de los ciudadanos, y las estipulaciones constitutivas del derecho. Es aquí donde se juega el éxito o el fracaso del proyecto político de la democracia constitucional. Eso nos obliga a abrir nuestra perspectiva de análisis y a tomar en consideración la dimensión pragmática de la teoria y la ciencia del derecho. Así lo reconoce el propio Ferrajoli cuando sugiere que la lucha por el garantismo pasa por la construcción de significados compartidos, de un sentido común jurídico de juristas y legos, al que apela el sentido claro de las palabras de la constitución o de la ley (2007, t. I, 21 y ss).

Esta última referencia nos pone sobre la pista de un factor decisivo para entender cómo funciona realmente ese contexto institucional de los derechos políticos al que he aludido en páginas anteriores. La distinción de dos funciones básicas, la diferencia entre legis-latio y iuris-dictio, entre decidir el derecho y decir el derecho, entre legislar y aplicar y, en última instancia, entre opinar y juzgar alude implícitamente a un conjunto de evidencias pragmáticas que están expuestas al cuestionamiento constante por parte del público. Desde la teoría del derecho es posible reconstruir los presupuestos epistémicos de la ciencia jurídica ${ }^{11}$, pero su eficacia depende en última instancia de lo que acontezca en el ámbito de la opinión pública, que es el lugar en el que se desarrollan los procesos básicos de formación de la voluntad política y donde se contrastan -pragmáticamente- las estipulaciones básicas del lenguaje jurídico. En este sentido, la distinción entre funciones de gobierno y funciones de garantía alude implícitamente a modelos socialmente compartidos de distribución de la autoridad política y de la autoridad epistémica, a reglas que delimitan el ámbito de competencias del político y el científico, del legislador y el experto (cfr. Broncano, 2006). La cuestión que me interesaba suscitar en estas páginas se sitúa en este terreno. Hoy nos enfrentamos a una serie de transformaciones socio-culturales de amplísimo calado que ponen en cuestión las pautas de distribución del trabajo epistémico que estaban vigentes en tiempos de Locke, Sieyes y Montesquieu, cuando la separación de poderes fue formulada históricamente, y que subyacen a la identificación entre funciones de gobierno y poderes de carácter "político", por un lado, y funciones de garantía y poderes de carácter "técnico", por otro. 
En otros términos, me parece interesante observar que el deterioro de los mecanismos institucionales de separación de los poderes no es más -ni menos- que una consecuencia de un cambio social más amplio, que tiene que ver con la disolución de la frontera entre lo opinable, que es objeto de decisión política, y lo cierto, que puede ser determinado con la objetividad del conocimiento experto. No estoy diciendo que no exista la objetividad, o que no sea posible aproximarse a ella, ni en materia moral ni en el conocimiento de la naturaleza, o en el campo del derecho. Me limito a observar que, en la próctica, han cambiado las reglas de distribución del trabajo epistémico. El peso del conocimiento experto no sólo en el ámbito de la administración, sino en el de la legislación, es cada vez más alto, hasta el punto de que esta distinción tiende a quedar desvirtuada, con todos los riesgos de una indebida cesión de responsabilidades de la política que acaba poniendo el gobierno en las manos irresponsables de los expertos. $Y$ otro tanto sucede en el campo de la jurisdicción. Viceversa, asistimos a una verdadera contraofensiva anti-ilustrada que persigue una reapropiación teológica, o simplemente demagógica, de los consensos fundamentales que habia alcanzado a lo largo del siglo XX la tradición jurídica y política del constitucionalismo democrático.

Lo importante, en todo caso, es observar cómo la frontera entre la esfera de lo decidible y la esfera de lo no decidible, entre poderes de disposición y poderes de cognición, en el lenguaje de Ferrajoli ${ }^{12}$, se ha vuelto mucho más conflictiva de lo que era en otro tiempo. Los márgenes de incertidumbre se multiplican y no sólo dentro del ámbito (relativamente) formalizado en que opera la ciencia jurídica, sino también, y sobre todo, fuera de ese ámbito, en el plano pragmático, donde se juega la efectividad o inefectividad de sus convenciones constitutivas. Cuando el lenguaje artificial del derecho se enfrenta a la realidad se comprueba si las palabras de la constitución son transparentes y significativas 0 , por el contrario, están vacías de contenido. No puede ser de otra manera cuando se observa -como no deja de hacer el propio Ferrajoli- que tanto el lenguaje del legislador como el de la ciencia jurídica son lenguajes que bordean el lenguaje natural, que se encuentran inevitablemente contaminados por sus oscilaciones ${ }^{13}$. Como deciamos más arriba, cuando los procesos de entendimiento público están tan alterados que ya no es posible contrastar las estipulaciones básicas del lenguaje jurídico, cuando el jurista más riguroso no atina a restablecer de manera fiable la frontera entre lo opinable y lo cierto, la distinción entre decir y aplicar se vuelve inestable, y con ella el equilibrio de un mecanismo institucional tan frágil como el de la separación de poderes.

No son discusiones de laboratorio, puras especulaciones metodológicas, alejadas de la democracia "real". Sabemos que uno de los factores que en el futuro van a condicionar -están condicionando ya, mucho más de lo que estamos dispuestos a admitir- el desarrollo de nuestras instituciones democráticas es la radical concentración del conocimiento experto en pocas manos y en pocos centros de poder, con la consiguiente disolución de las fronteras entre poder político, económico e ideológico. En el horizonte de nuestras democracias aparece el fantasma de su disolución tecnocrática a manos de poderes que disponen de una superioridad epistémica manifiesta, absolutamente incontrolable. La raíz de los males está en la clamorosa transformación de los equilibrios de saber-poder entre los distintos agentes institucionales. Las batallas políticas fundamentales son cada vez más, en nuestros días, batallas por la información. No en vano las más recientes experiencias de reforma institucional basadas en las propuestas de la new governance buscan por todos los medios mejorar la calidad epistémica de las decisiones. Se piensa que una iniciativa de gobierno cualquiera está inevitablemente destinada al fracaso si no logra cooptar a los que más saben. En la lógica de la democracia convendría no perder de vista la otra cara de la moneda, esto es, que la lucha por la recuperación de la autoridad epistémica perdida se hace a costa de la dispersión de las funciones constitucionales y va en detrimento de los derechos de participación de los que menos saben. La moraleja es siempre la misma: la confusión de los poderes diluye el componente igualitario que caracteriza a los derechos políticos.

Recibido: 20 de enero de 2009

Aceptado: 23 de febrero de 2009 
1 La idea de enfocar el análisis sobre la cuota efectiva de poder de que realmente dispone cada elector está tomada de Meaglia, 2006.

2 En el campo de la ciencia política el eclipse del interés por los derechos políticos viene de lejos. A distancia de algunas décadas puede decirse que la derrota de la teoría "clásica" de la democracia y el éxito de las alternativas de derivación schumpeteriana ha sido clamoroso. En los análisis comparatistas contemporáneos la dimensión de la participación tiende a ser identificada con la representación de los inputs del sistema político y la legitimidad del sistema con la sensibilidad a las preferencias de los agentes. Me he ocupado de las implicaciones prácticas de estas opciones conceptuales en Greppi, 2008.

3 Obviamente, no es éste el lugar para trazar un panorama siquiera sintético del debate. Un balance aparece en Bayón, 2004. Véanse también los ensayos recogidos en Carbonell, 2003. Sobre las raíces conceptuales del constitucionalismo democrático Salazar Ugarte, 2006.

4 En los conocidos términos de Rawls, las reglas de la democracia responden al modelo de la justicia procedimental imperfecta y nunca al de la justicia procedimental pura. Los criterios de justicia son independientes respecto de los resultados del procedimiento democrático (Rawls, 1995, apdo. 14).

5 Dado que el correcto balance de razones habrá de ser actualizado caso por caso, cabe plantearse el desafío del particularismo, en alguna de sus versiones. Cuando se asume una noción exigente de justificación, no es fácil establecer barreras a considerar la totalidad de las razones relevantes del caso y la posibilidad de revisar cada decisión (cfr. Celano, 2002).

6 Un interesante análisis histórico que desmiente la reconstrucción centrada en el constitucionalismo de los derechos, se encuentra en Bellamy, 1996. En referencia a la tradición constitucional europea, véase las distinciones conceptuales recogidas en Barberis, 2001.

7 Cuatro razones justifican, en opinión de Ferrajoli, el abandono de una concepción meramente procedimental de la democracia: (1) ignora la realidad de los actuales Estados de derecho donde no existe poder alguno que no esté sujeto a la ley; (2) cualquier democracia tiene que proteger jurídicamente las condiciones (sustantivas) de su propia supervivencia; (3) existe un nexo material entre el ejercicio de la soberanía y el reconocimiento de los derechos; y (4) la delimitación del cuerpo político requiere normas sobre inclusión y exclusión de los sujetos que ejercen el derecho de autodeterminación y las modalidades de ejercicio. En suma, concluye Ferrajoli, en el comienzo de su extensa teoría normativa de la democracia, "para que un sistema sea democrático, [...] se precisa que [las mayorias] estén vinculadas a las necesidades, inmunidades y poderes -de todosque componen la soberanía popular" (2007, t. II, 6-9; 14).

8 Ferrajoli, 2007, t. II, 222; apdos. 10.19; $10.20 ; 12.13$. Sobre la relación entre cognitivismo en la interpretación de normas y separación de poderes, véase Martí, 2002; y Barberis, 2005.

9 Obsérvese que en esta situación, al final, acaba siendo imposible opinar sobre las formas y las ocasiones de ejercicio del poder político, un poder disperso y confuso es un poder irremediablemente opaco. Para una visión de conjunto en la amplisima literatura sobre (las dificultades de) el control de las instituciones de la gobernanza internacional, véase por ejemplo Held, 2004.

10 La cuestión es relevante tanto en ámbito local como trans-nacional. Sobre los problemas de control de estos órganos en ámbito europeo véase, por ejemplo, Benz, 2007 y Curtin, 2007.

11 Ferrajoli retoma esta cuestión en 2006, 93-98, en respuesta a De Lora, 2005 y Greppi, 2005.

12 Los poderes de disposición tienen un carácter "político", cuentan con una legitimación representativa y obedecen, en último término, al juego de mayorías y minorías. Los poderes de cognición, en cambio, son poderes por así decir -con la fórmula clásica- "nulos", que consisten en la verificación de la existencia de los presupuestos de hecho y de derecho de la aplicación de la ley y la calificación jurídica de sus propiedades relevantes (véase Ferrajoli, 2008, 427-430).

13 Sobre la relación entre los distintos niveles de lenguaje en la ciencia y en la dogmática jurídica véase Ferrajoli, 2004, y en especial el ensayo titulado "La formación y el uso de los conceptos en la ciencia jurídica y en la aplicación de la ley".

\section{BIBLIOGRAFÍA}

Barberis, Mauro (2001): "Divisione dei poteri e libertà da Montesquieu a Constant", en Materiali per una storia della cultura giuridica, n. ${ }^{\circ} 1$.

Barberis, Mauro (2005): "Separazione dei poteri e teoria giusrealista dell'interpretazione", en P. Comanducci, 
R. Guastini (eds.), Analisi e diritto 2004. Ricerche di giurisprudenza analitica, Torino, Giappichelli.

Bayón, Juan Carlos (2004): "Democracia y derechos: Problemas de fundamentación del constitucionalismo", en J. Betegón, F. Laporta, L. Prieto, J. R. de Páramo (coords.), Constitución y derechos fundamentales, Madrid, CEC.

Bovero, Michelangelo (1998): "La confusione dei poteri oggi", en Teoría política, n. 3.

Bellamy, Richard (1996): "The Political form of the Constitution: the Separation of Powers, Rights, and Representative Democracy", en Political Studies, vol. XLIV.

Benz, A. (2007): "Accountable Multilevel Governance by the Open Method of Coordination?", en European Law Journal, n. ${ }^{\circ} 4$.

Bovens, Mark (2001): "Analysing and Assessing Public Accountability. A Conceptual Framework", en European Governance Papers (EUROGOV), n. ${ }^{\circ}$ C-06-01.

Broncano, Fernando (2006): "Tres formas de reparar el error de Epimeteo: El conocimiento experto en la esfera pública", en Entre ingenieros y ciudadanos, Barcelona, Montesinos.

Carbonell, Miguel (ed.) (2003): Neoconstitucionalismo(s), Madrid, Trotta.

Celano, Bruno (2002): "Defeasibilitye bilanciamento. Sulla possibilità di revisioni stabili", en Ragion Pratica, vol. 18.

Curtin, Deirdre (2007): "Holding (Quasi-) Autonomous EU Administrative Actors to Public Account", en European Law Journal, n. ${ }^{\circ} 4$.
De Lora, Pablo (2005): "Luigi Ferrajoli y el constitucionalismo fortísimo", en M. Carbonell, P. Salazar (eds.), Garantismo. Estudios sobre el pensamiento jurídico de Luigi Ferrajoli, Madrid, Trotta.

Dworkin, Ronald (2003): Virtud soberana: La teoría y la práctica de la igualdad, Barcelona, Paidos.

Ely, John H. (1997): Democracia y desconfianza. Una teoría del control constitucional, Bogotà, Siglo del Hombre/ Universidad de los Andes.

Ferrajoli, Luigi (2004): Epistemología jurídica y garantismo, México, Fontamara.

Ferrajoli, Luigi (2006): Garantismo. Una discusión sobre derecho y democracia, Madrid, Trotta.

Ferrajoli, Luigi (2007): Principia luris, Roma-Bari, Laterza, 2 tomos.

Ferrajoli, Luigi (2008): "Principia iuris. Una discusión teórica", en Doxa. Cuadernos de filosofía del derecho, vol. 31.

Greppi, Andrea (2005): "Democracia como valor, como ideal y como método", en M. Carbonell, P. Salazar (eds.), Garantismo. Estudios sobre el pensamiento jurídico de Luigi Ferrajoli, Madrid, Trotta, Madrid.

Greppi, Andrea (2008): "Democrazie dimezzate. Qualità democratica e autocrazia", en Teoría política, 2008, n. ${ }^{\circ}$, pp. 5-22.

Guastini, Riccardo (1998): "Separazione dei poteri o divisione del potere?", en Teoría política, n. ${ }^{\circ}$ 3, pp. 25-42.

Held, David (2004): "Democratic Accountability and Political Effectiveness from a Cosmopolitan Perspective", en Government and Opposition, n. ${ }^{\circ} 2$.
Hierro, Liborio (2007): "Los derechos humanos en la sociedad democrática", en Revista jurídica de la Universidad Autónoma de Madrid, vol. 15, pp. 109-124.

Kaldor, Mary (2005): La sociedad civil global, Barcelona, Tusquets.

Marti, José Luis (2002): "El realismo juridico: ¿Una amenaza para el liberalismo y la democracia?", en Isonomía, vol. 17

Meaglia, Piero (2006): I/ potere dell'elettore. Elezioni e disuguaglianza politica nel governo democratico, Troina, Città Aperta.

Nino, Carlos S. (1997): La constitución de la democracia deliberativa, Barcelona, Gedisa.

Rawls, John (1995): Teoría de la justicia, 2. edición, México, F.C.E., México, 21995, apdo. 14.

Salazar Ugarte, Pedro (2006): La democracia constitucional. Una radiografía teórica, México, F.C.E.

Troper, Michel (2001): "Actualidad de la separación de poderes", en Por una teoría jurídica del Estado, Madrid, Dykinson/Universidad Carlos III de Madrid, pp. 203-216.

Vile, Maurice J. C. (2007): Constitucionalismo y separación de poderes, Madrid, CEPC.

Waldron, Jeremy (2005): Derecho y desacuerdos, Madrid-Barcelona, Marcial Pons.

Zagrebelsky, Gustavo (1995): El derecho dúctil. Ley, derechos, justicia, Madrid, Trotta.

Zürn, Michael; Joerges, Christian (eds.) (2005): Law and Governance in Postnational Europe, Cambridge, Cambridge University Press. 